\title{
Çevre Mühendisliği Eğitiminde Ekosistem/Havza Yönetimi Bilincinin Önemi
}

\author{
Vedat Yilmaz ${ }^{1, *}$ \\ ${ }^{1}$ Artvin Çoruh Üniversitesi, Mühendislik Fakültesi, Çevre Mühendisliği Bölümü, 08100, Seyitler, Artvin.

\section{Özet}

Öncelikle sağlıklı içme suyu temini ve atıksuların uzaklaştırılması üzerinde yoğunlaşmış olan çevre mühendisliği pek çok farklı mühendislik disiplinin çalışma alanını bünyesinde barındırmakla birlikte, 70'li yıllardan bu yana gelinen süreçte altyapı faaliyetleri, iklim değişimi, atık yönetimi, iş ve işçi sağllğ̆, çevre yönetimi gibi çok geniş bir alanda mesleki çalışmalar yürütmektedir. Değişen teknolojik yaklașımlar ve toplumsal gereksinimlere koșut olarak mühendislik uzmanlı alanları da yıllar içerisinde değișim ve dönüsüm geçirmektedir. Her türlü çevre sorunu yerel sinırların ötesinde olup, mühendislik uygulamalarının ekosisteme etkisinin bütüncül etkileşimlerini küresel ölçekte anlayabilmek gerekmektedir. Örneğin, aynı nehir havzasında birbiri ardı sira inşa edilen büyük barajların yanı sıra onlarca nehir tipi hidroelektrik santrali projeleri de hayata geçirilmektedir. Her bir baraj ve santralin tekil çevresel riskleri dikkate alınması yeterli olmamakta, domino etkisi ile çok daha büyük küresel sorunların bir parçası olup olmayacă̆ modellenebilmelidir. Bu amaçla faaliyetlerin ekosistem üzerinde oluşturacă̆ etkilerini anlamak üzere Çevresel Etki Değerlendirmesi (ÇED), Çevresel Risk Değerlendirmesi (ÇRD) ve Yaşam Döngü Analizi (YDA) gibi araçlarla değerlendirilmesi kaçınılmazdır. Bugün ülkemizde 52 üniversitede bulunan çevre mühendisliği bölümünün 46'sında lisans eğitimi verilmekte olup, bu bölümlerde hem ders müfredatı hem de ögretim üyelerinin uzmanlık alanları çok farklılık göstermektedir. Dolaylsıyla çevre yönetimi bilgi birikimi ve deneyimi aynı düzeyde olamamaktadır. Bu amaçla başta Mühendislik Eğitim Programları Değerlendirme ve Akreditasyon Derneği (MÜDEK) akreditasyon süreçlerine bu yönde ölçüt getirilmelidir. Bu çalışmada öncelikli olarak çevre sorunlarının çözümünde havza yönetiminin önemi ortaya konulmuş, ülkemizdeki çevre mühendisliği bölümlerinde verilen derslerde ekosistem/havza yönetimi bilincinin öğretilme düzeyi dĕgerlendirilmiștir.

\section{Anahtar Sözcükler}

Çevre Mühendisliği Eğitimi, Ekosistem, Havza Yönetimi

\section{The Importance of Ecosystem/Watershed Management Knowledge in Environmental Engineering Education}

\begin{abstract}
Although environmental engineering -primarily focusing on healthy water supply and disposal of wastewater-incorporates study areas of various engineering disciplines, it has also undertaken a wide range of activities such as infrastructure activities, climate change, waste management, health and safety, environmental management and etc. since 70's. The areas of engineering expertise, in line with changing technological approaches and social needs, are undergoing change and transformation over the years. Environmental problems are beyond local boundaries and it is necessary to understand the holistic (integrated) interactions of the effects of engineering applications over ecosystems on a global scale. For example, big dams have been built as well as projecting dozens of river-type hydropower projects in the same river basin. The environmental risks of each individual project should be modeled but also the overall domino effects should take into consideration. It is inevitable to evaluate the effects that the activities will have on the ecosystem with some tools such as Environmental Impact Assessment (EIA), Environmental Risk Assessment (ERA) and Life Cycle Analysis (LCA) for this purpose. Today, out of 52 universities in Turkey, 46 of them gives undergraduate level education in their environmental engineering departments and both the departmental curriculum and the specialization of the faculty members are very different in these departments. Therefore, the knowledge and experience of environmental management cannot be at the same level. This should be taken into consideration in the accreditation process by the Association of Engineering Education Programs Evaluation and Accreditation (MÜDEK). In this study the priority of watershed management to solve the environmental problems was verified, and the level of ecosystem/watershed management awareness was evaluated in the undergraduate course curriculums of environmental engineering departments in our country.
\end{abstract}

$\underline{\text { Keywords }}$

Environmental Engineering Education, Ecosystem, Watershed Management 


\section{Giriş}

19. yüzyılın tanık olduğu endüstri devrimi ile birlikte hissedilmeye başlanan çevre sorunları, 20. yüzyılın başlarında "kamu sağlığı" (puclic health) mühendisliği adı altında incelenmeye başlanmış ve "sağlık mühendisliği" (sanitary engineering) adını almış, üniversitelerde bu konu ile ilgili olarak araştırma ve eğitim faaliyetlerine hız verilmiştir. Yüzyılımızın sonuna doğru ise çevre sorunları son derece geniş bir yelpazeye yayılmış ve artık bağımsız ancak çokdisiplinli bir araştırma konusu haline gelerek "Çevre Mühendisliği" adını almış, gerek lisans gerekse yüksek lisans ve doktora eğitimleri çok sayıda üniversitede verilmeye başlanmıştır.

Mühendislik alanı olarak yüz yıllık bir geçmişi olsa da erken Mısır dönemine ait (M.Ö.3400-2450) arkeolojik kazılarda yağmur sularının toplanması ve evsel atıksuların deşarjı için bakır boruların kullanıldığı anlaşııışstır. Roma döneminde (M.Ö.900- M.S.476) büyük su kemerleri, sarnıçlar ve kanalizasyon sistemleri inşa edilmiş, içme suyunun tat ve berraklı̆̆ını geliştirmek için birçok doğal maddeler kullanılmıştır (Şengül ve Yurtsever 2011). 1956'da Washington Üniversitesi'nde Sağlık Mühendisliği adı altında çevre kirliliği ve çevre yönetimi sahasında faaliyet gösteren bir mühendislik dalı kurulmuştur (Corbitt 1989).

Peker (2011), çevre mühendisliğini "çevreyi, zararlı insan faaliyetlerinden ve insanları da olumsuz çevre şartlarından korumayı amaçlayan mühendislik dalıdır" şeklinde tanımlamaktadır. ABD İnşaat Mühendisleri Odası (ASCE), çevre mühendisliğinin amaç ve tanımını şu şekilde yapmaktadır: çevre mühendisliği, çevre sağlığı problemlerinin çözümünde teori ve pratiğin öğretildiği bir mühendislik dalıdır. Çevre mühendisleri ve bu alanda çalışan bilim insanları, özellikle halk sağlığının korunması için aşağıdaki konularda araştırma yapar ve teknoloji üretirler;

- Temiz ve yeterli içme suyu temini,

- Atık suların arıtılması veya tekrar kullanımı,

- Katı atıkların bertarafi veya geri dönüşümü,

- Şehir ve kırsal bölgelerde yeterli kanalizasyon ve atıksu arıtma tesislerinin yapımı,

- Hava, toprak ve su kirliliğinin sürekli kontrolünün sağlanması,

- Bu çözümlerin sosyal ve çevresel etkilerinin kontrolünün yapılması ve

- Teknolojik gelişmelerin çevre üzerindeki etkilerinin araştırılması.

Çevre mühendislerinin en yoğun olarak istihdam edildiği kamu kurumu olan Çevre ve Şehircilik Bakanlığı'nın görevleri arasında; çevrenin korunması, iyileştirilmesi ile çevre kirliliğinin önlenmesine yönelik prensip ve politikalar tespit etmek, standart ve ölçütler geliştirmek, programlar hazırlamak; bu çerçevede eğitim, araştırma, projelendirme, eylem planları ve kirlilik haritalarını oluşturmak, bunların uygulama esaslarını tespit etmek ve izlemek, iklim değişikliği ile ilgili iş ve işlemleri yürütmek olarak ifade bulmuştur (URL-1 2018). Çevre mühendislerinin yoğun olarak çalıştığı bir diğer kurum olan Orman ve Su İşleri Bakanlığı'nın görevleri arasında;

- Su kaynaklarının korunmasına ve sürdürülebilir bir şekilde kullanılmasına dair politikalar oluşturmak, ulusal su yönetimini koordine etmek,

- toprağın korunması ve tabii kaynakların geliştirilmesi amacıyla; havza bütünlügü̈ esas alınarak, çölleşme ve erozyonla mücadele, çı̆̆, heyelan ve sel kontrolü ile entegre havza islahı plan ve projelerini yapmak, yaptırmak, uygulanmasını izlemek, bu faaliyetlere proje bazında destek sağlamak, bu iş ve işlemlerle ilgili politika ve stratejiler belirlemek, ilgili kurum ve kuruluşlar arasında işbirliği ve koordinasyon sağlamak,

- Su havzalarının geliştirilmesine yönelik ulusal ve bölgesel düzeyde planlama yapmak, politika ve stratejiler belirlemek,

- Havza bazında kirliliğin önlenmesi ile ilgili tedbirleri ilgili kurum ve kuruluşlarla birlikte belirlemek, değerlendirmek, güncellemek ve uygulamaların takibini yapmak.

- Su kaynaklarının korunması ve yönetimi ile ilgili uluslararası sözleşmeler ve diğer mevzuattan kaynaklanan süreçleri takip etmek, sınır aşan ve sınır oluşturan sulara ilişkin işleri ilgili kurumlarla işbirliği içinde yürütmek olarak siralanmıştır (URL-2 2018).

Bu çalışmada öncelikle ülkemizde çevre mühendisliğinin gelişimi, çevre mühendisliğinin görev ve çalışma alanları ile çevre mühendisliği eğitiminde havza yönetiminin önemi ve lisans programlarında verilen derslerde havza yönetimi eğitim düzeyi değerlendirilmektedir.

\section{2. Ülkemizde Çevre Mühendisliğinin Gelişimi}

Ülkemizde Çevre Mühendisliği Bölümü (ÇMB) ilk olarak 1973 yılında Orta Doğu Teknik Üniversitesi'nde (ODTÜ) kurulmuş, lisans eğitimi ise 1975 yılında Ege Üniversitesi'nde başlamıştır. 1978 yılında İTÜ ve ODTÜ'de çevre mühendisliği bölümleri öğretime başlamıştır (Samsunlu 1991). 1970'li yıllarda ilk çevre mühendisliği bölümlerinin kurulmaya başlandığı ve kadrolaşmanın da bunun devamında geliştiği ilk yıllarda, Çevre Mühendisliğindeki akademisyenlerin ağırlıklı olarak, Kimya Mühendisliği, İnşaat Mühendisliği, Biyoloji, Kimya, Ziraat Mühendisliği, Jeoloji Mühendisliği ve Orman Mühendisliği gibi çeşitli meslek gruplarından oluştuğu, birçok üniversitede Çevre Mühendisi kökenli öğretim üyesinin olmadığ 1 ve olanlarda ise genel öğretim üyesi sayısı içerisinde oldukça düşük sayıda Çevre Mühendisi kökenli öğretim üyesinin mevcut olduğu belirtilmektedir (Zeren 1997). 
Türkiye'de devlet üniversiteleri temel alındığında 2017 yılında toplam 113 adet üniversite bulunmaktadır. Devlet üniversitelerinin 52'sinde ÇMB bulunmaktadır. Ayrıca iki vakıf üniversitesinde mevcut olan ÇMB önceki yıllarda kapatılmıştır (Tablo 1). Bu üniversitelerin altısında henüz lisans eğitimi verilmemektedir. Bunun yanı sıra, halen 3 üniversitede devam etmekle birlikte bugüne kadar 20 bölümde çevre mühendisliği eğitimi ikinci öğretim olarak da verilmiştir. Üniversitelerin ÇMB'nde genel olarak öğrenim dili Türkçe olmakla birlikte 6 ÇMB'nde öğrenim dili olarak İngilizce kullanılmaktadır. Üniversite tercih kılavuzları kontenjan bilgileri değerlendirildiğinde, 90'lı yıllarda bölüm sayısı ve kontenjanlarda hızlı bir büyümenin olduğu, 2000’li yıllarda bu artışın durağanlaştığı ve günümüzde azalma yönünde ilerlediği görülmektedir (Şekil 1). Şimdiye kadar üniversitelerden yirmi bini aşkın çevre mühendisi mezunu verildiği tahmin edilmektedir.

Tablo 1: Çevre mühendisliği bölümleri 2017-2018 akademik dönemi üniversite tercih kontenjan sayıları (URL-3 2018)

\begin{tabular}{|c|c|c|c|c|c|c|c|c|c|c|c|}
\hline \multirow{2}{*}{ Üniversite } & \multicolumn{2}{|c|}{ Kontenjan } & \multirow{2}{*}{ Akreditasyon } & \multirow{2}{*}{ Üniversite } & \multicolumn{2}{|c|}{ Kontenjan } & \multirow{2}{*}{ Akreditasyon } & \multirow{2}{*}{ Üniversite } & \multicolumn{2}{|c|}{ Kontenjan } & \multirow{2}{*}{ Akreditasyon } \\
\hline & Ö.Ö. & İ.Ö. & & & Ö.Ö. & İ.Ö. & & & Ö.Ö. & İ.Ö. & \\
\hline A.İ. Baysal & 30 & - & - & Düzce & 20 & - & - & Munzur & $10^{*}$ & $55^{* *}$ & - \\
\hline Adiyaman & $40 *$ & - & - & Erciyes & 40 & $60 * *$ & MÜDEK & Muş & $* * *$ & & - \\
\hline Akdeniz & 60 & - & - & Firat & 15 & $70 * *$ & - & N. Kemal & 30 & 60 & - \\
\hline Aksaray & $60 *$ & $30 * *$ & - & Gebze YTE & 50 & - & - & N. Erbakan & 15 & - & - \\
\hline Anadolu & 70 & - & MÜDEK & Giresun & $50 *$ & - & - & N.H.B.Veli & $60 *$ & - & - \\
\hline Ardahan & $40^{*}$ & - & - & Gümüşhane & $* * *$ & & - & Niğde Ö.H. & $30 *$ & - & - \\
\hline A. Çoruh & $20 *$ & - & - & Hacettepe & 50 & - & - & O. Mayıs & 60 & $70 * *$ & - \\
\hline Atatürk & $60 *$ & $90 * *$ & MÜDEK & Harran & $40 *$ & - & ABET & ODTÜ & 65 & - & ABET \\
\hline Balıkesir & 50 & $50 * *$ & - & İTÜ & 115 & - & - & Pamukkale & 40 & $50^{*}$ & MÜDEK \\
\hline Bartın & $60 *$ & $50 * *$ & - & İstanbul & 80 & - & - & Sakarya & 80 & 20 & MÜDEK \\
\hline Batman & $* * *$ & & & Gümüşhane & $* * *$ & & & Selçuk & 35 & - & MÜDEK \\
\hline B. Eren & $40^{*}$ & 45 & - & K.S. İmam & 15 & $50 * *$ & - & Siirt & $* * *$ & & - \\
\hline B. Teknik & 50 & - & - & Karabük & 15 & $85 * *$ & - & Sinop & 60 & & - \\
\hline B. Ecevit & 15 & $40 *$ & MÜDEK & K. Çelebi & $* * *$ & & - & S. Demirel & 20 & $60^{*}$ & MÜDEK \\
\hline Cumhuriyet & $60 *$ & $85^{*}$ & MÜDEK & K. 7 Aralık & $* * *$ & & MÜDEK & Uludağ & 70 & - & - \\
\hline Ç. 18 Mart & 50 & - & - & Kocaeli & 80 & 50 & MÜDEK & Y. Teknik & 70 & $70 * *$ & MÜDEK \\
\hline Çukurova & 50 & 20 & - & Marmara & 60 & - & MÜDEK & V.Y. Y1l & 15 & - & - \\
\hline D. Eylül & 80 & - & MÜDEK & Mersin & 20 & - & & & & & \\
\hline
\end{tabular}

Ö.Ö.: Örgün öğretim, İ.Ö.: İkinci öğretim

*: 2016 yılı kontenjanı, **: 2015 ve öncesi kontenjanı, ***: Lisans eğitimi yok

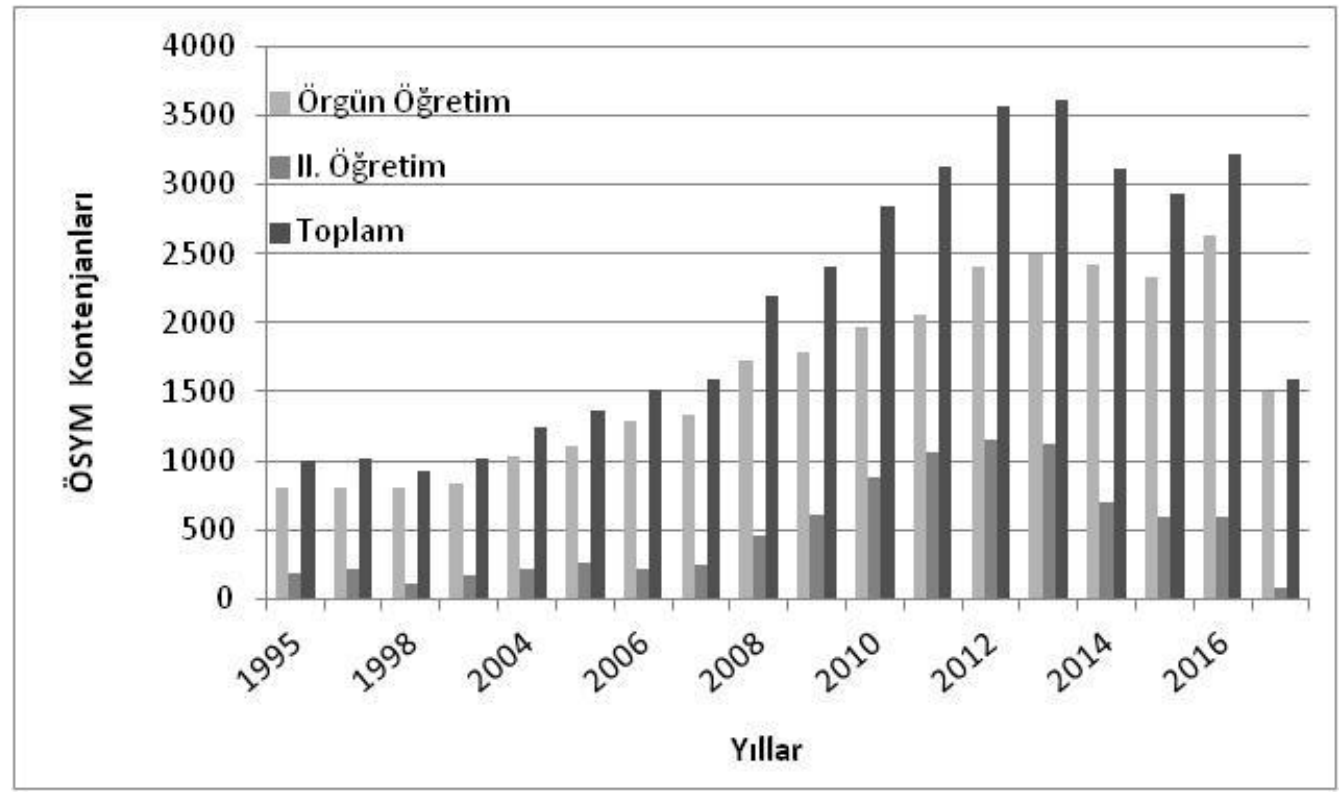

Şekil 1: 1995-2017 yılları arasında çevre mühendisliği bölümlerine ayrılan toplam kontenjan sayıları

Eğitim programlarında benzerlikler bulunmakla birlikte akademik kadro, laboratuvarlar, kütüphane, vb. değişik faktörlerin etkisiyle eğitim kalitesinde farklılıklar olduğu bir gerçektir. Bu farklılıkların giderilmesi için gerek mezunlarının gerekse de programların birbirleriyle karşılaştırılabilmesini sağlayacak daha somut değerlendirme araçlarının kullanılmasına ihtiyaç vardır. ÇMB'leri de bu amaçla, eğitim kalitesi düzeyinin ulusal (MÜDEK) ve uluslararası (ABET - yükseköğretim kurumlarının uygulamalı bilim, mühendislik, teknoloji ve bilişim alanlarındaki programlarını akredite eden ve kar amacı gütmeyen ABD merkezli bir örgüt) standartlara koşut olduğunu belgelemek üzere 2017 yılı itibari ile 14 üniversitede MÜDEK, 2 üniversitede ABT akreditasyonu alınmıştır. 


\section{3. Çevre Mühendisliği Eğitimi}

Çevre Mühendisliği’nin çerçevesi içinde biyoloji, kimya, inşaat mühendisliği, kimya mühendisliği, makine mühendisliği, çevrebilim, jeoloji, çevre hukuku, halk sağlığı ve nükleer mühendisliği gibi birçok bilim dalı yer almaktadır. Doğal dengeyi koruyarak, gelişen teknolojiye koşut olarak sürdürülebilir kalkınmayı sağlayabilecek çevre politikaları geliştirebilmek için yetkin Çevre Mühendislerinin yetiştirilmesini gerektirmektedir. Çevre Mühendisliği, diğer mühendislik dallarından farklı olarak, doğanın kaynaklarını tüketmeyi değil, doğaya sahip olduklarını geri vermeye çalışan bir mühendislik dalıdır.

Çevre mühendisliği, yerel ve küresel ölçekte, çevreyi insan faaliyetlerinin olumsuz etkilerinden korumak, insan sağlı̆̆ ve refahı için çevre koşullarını iyileştirmek yönünde temel bilimsel kavramları uygulamaya koyan mühendislik dalıdır. Her iki tanımda ortak olan en önemli nokta, bilginin uygulamaya konma sürecidir. Bu tanım temel alınarak geliştirilen çevre mühendisliği programı, gelişen teknolojiyle ortaya çıkan toprak, su ve hava kirliliğinin giderilmesi konusunda yapılacak çalışmaların tasarımı, projelendirilmesi ile insan sağlı̆̆ı ve refahına uygun çevre koşullarının sağlanması konularında eğitim ve araştırmalar yapmaktadır. Çevremizdeki etkinlikler arasında yaşam için gerekli uyumu bozan etmenleri ortaya çıkarma ve yeni uyumsuzluklara yol açmadan bunları ekonomik olarak giderme amacı taşımaktadır.

Çevre mühendisleri, gerçekleştirilen tüm üretim ve tüketim etkinliklerinin insan sağlığına, refahına ve doğal dengeye zarar vermeyecek biçimde düzenlenmesi için gereken önlemleri araştırmaktadırlar. Her çeşit atık ve atıkların canlı ve cansız varlıklara zarar vermeye başladığı sınır değerleri saptamakta, yerleşim merkezlerinin su şebekesi, kanalizasyon gibi altyapı sistemlerinin insan sağlığına en uygun biçimde inşa edilip işletilmesi için gerekli önlemlerin alınması için çalışmaktadırlar.

Çevre mühendisliği, atıksu arıtımı, temiz su getirme gibi kentsel problemlere çözüm bulmak amacıyla ortaya çıkan bir mühendislik dalı iken, çözülmesi gereken çevre problemlerinin boyut ve şekil değiştirmesiyle, ilgi alanları genişlemektedir. Küresel ısınma, eser miktarda insan kaynaklı kirleticilere uzun süre maruz kalma nedenleriyle oluşan kronik problemler ve benzeri sorunlar, çevre mühendisliği için yeni araştırma ve çalışma alanlarının doğmasına sebep olmaktadır. Bugün çevre mühendisleri toprak ve yeraltı suyu temizleme, toksikoloji, risk analizi, kirlilik taşınımı ve proses tasarımlarını içeren konularla da ilgilenmektedirler (Aksoy ve İmamoğlu 2011).

Çevre mühendisliği, çevre sistemlerinin karmaşık olması, yeni çevresel problemlere dinamik bir şekilde çözüm bulma gerekliliği ve çevre problemlerinin çeşitliliği nedenleriyle, artık tüm dünyada kabul edilen ayrı bir disiplin haline gelmiştir. Son yıllarda çevre mühendisliği alanında çalışan akademisyen ve profesyoneller, gelecekteki çevre mühendisliği araştırma alanları ve eğitimi konularındaki öngörülerini çeşitli platformlarda (akademik dergi, rapor, çalıştay ve/veya sempozyum) beyan etmektedirler (Aksoy ve İmamoğlu 2011).

Çevre mühendisliği dalının disiplinler arası çalışıyor olması ve günün şartlarına göre sürekli yenileniyor olması, çevre mühendisliğinde eğitim konusunu sürekli tartışılır hale getirmiştir. Çevre Mühendisliği eğitiminin ilk y1lında temel mühendislik dersleri, ikinci yılında temel branş dersleri, üçüncü ve dördüncü yıllarında ise mesleki dersler verilmektedir. Çevre mühendisliği eğitimi alan bir öğrencinin dört yıl boyunca almış olduğu dersler, üniversiteden üniversiteye değişmektedir. Bu eğitim öğretim farklılığının muhtemel sebebi, öğretim üyelerinin branşlaşmış oldukları konularla ilişkilidir. Özellikle ders programlarındaki ve içeriklerindeki değişikler, üniversitelerden farklı formasyonlarda çevre mühendisleri yetişmesine sebep olmaktadır. Ayrıca yapılan araştırmalar sonucu birçok üniversitede, mesleki derslerde genellikle su/atıksu mühendisliği konularına çok fazla yer verildiği ve bu bağlamda, su kirliliği ve kontrolü, su getirme ve kanalizasyon, su/atıksu arıtımı ve ileri arıtım gibi derslerin oldukça yoğun gösterildiği tespit edilmiştir (Peker 2011).

Avrupa'da Çevre Mühendisliği eğitimi kapsam olarak belirgin tanımlamalara ve sınırlamalara sahip değildir. Üniversitelerde Çevre Mühendisliği eğitimi alt yapısını oluşturan geleneksel meslek dallarından (halk sağlı̆̆ ve hijyen, inşaat, makine ve kimya mühendisliği, kimya, mikrobiyoloji, biyoloji vb.) fazlasıyla etkilendiğinden, eğitim programlarında çok çeşitlilik bulunmaktadır.

Katı atık yönetimi, hava kirliliği ve kontrolü, toprak kirliliği ve kontrolü gibi çevre mühendisleri için su/atıksu konuları kadar önemli olan diğer konular ise birçok üniversitede eğitim programlarında sınırlı sayıda derslerle verilmektedir. Türkiye'de verilen çevre mühendisliği eğitimi, Avrupa ve Kuzey Amerika ile karşılaştırıldığında, Türkiye açısından en önemli farkın müfredatta ağırlıklı olarak su arıtımı, su getirme ve kanalizasyon derslerinin verildiği görülmektedir. Buna karşılık, Avrupa ve Kuzey Amerika'daki üniversitelerde verilen derslerin ise üçte birinin toprak kirliliği, üçte birinin su kirliliği ve geriye kalan kısmın da hava kirliliği konularında yoğunlaştığı tespit edilmiştir (Peker 2011). Bununla birlikte, ABD’de pek çok üniversite, çevre mühendisliği programları müfredatlarında esneklik sağlayarak doğa bilimleri, uygulamalı mühendislik gibi alanlarda seçmeli dersler de vermektedirler.

Keskinler (2011)'in tespitine göre Ülkemizde genelde ileri teknoloji olarak bilinen Çevreye Duyarlı Teknolojilerin (ÇDT) uygulanması zor, pahalı teknolojiler olduğu ve ülke standartlarına uymayacağı şeklinde yanlış bir görüş hâkimdir. TÜBITTAK-TTGV'nin oluşturduğu Bilim-Teknoloji-Sanayi Tartışmaları Platformunca oluşturulan raporda ÇDT; "çevreyi koruyan, daha az kirleten, tüm kaynakları daha sürdürülebilir şekilde kullanan, atık ve artıkları daha yüksek oranlarda yeniden dönüştürebilen ve atıkları daha kabul edilebilir şsekilde bertaraf eden teknoloji” şeklinde tanımlamaktadır. Ülkemizin Avrupa Birliği uyum süreci çalışmaları "Entegre Kirlilik Önleme ve Kontrol” (EKÖK) kavramının uygulamaya geçmesi ile başlamış bulunmaktadır. Bilindiği gibi EKÖK, AB üyesi ülkelerde sanayi kuruluşlarının sadece deşarj ve emisyonlar için limit değerler konularak kirlenmenin kontrolü yerine, kirlenmenin üretim 
süreci ile birlikte değerlendirildiği bir yaklaşımdır. EKÖK yönetimi bu yönde düzenlemeler içermekte, çalışma izinlerinin çevresel performans adına denetlenmesini getirmektedir. Çevre Mühendisinin görevleri oldukça geniş olmakla birlikte bu makale kapsamında değerlendirildiğinde üç grupta toplamak mümkündür.

a. Cevre yönetimi ve çevresel etki değerlendirmesi: Doğal ortamlar, yeryüzündeki yaşamın sürdürülebilmesi için en önemli kaynaklardan birisidir. Bu kaynakların tanımlanması, özelliklerinin belirlenmesi ve insan kullanımı sonucu oluşacak kirliliğin etkilerinin azaltılması, kontrolü veya minimize edilmesi için biyolojik, kültürel, sosyal ve ekonomik koşulların da dikkate alınarak gerekli çevresel kararların verilmesi, alınması gereken önlemlerin planlanması ve uygulanması, ÇED raporlarının hazırlanması, etüt ve danışmanlık hizmetlerinin yapılması da çevre mühendislerinin temel görevleri arasında yer alır.

b. Risk analizi ve yönetimi: İnsan sağlığı ve çevreyle ilgili sistemler üzerinde kimyasalların oluşturduğu risklerin değerlendirilmesi, oluşabilecek tehlikelere uygun cevap verebilecek, tehditlerin etkisini ve olma ihtimalini azaltacak hazırlıkları, prosedürleri ve kontrolleri teşhis etmek de çevre mühendislerinin görevleri arasındadır.

c. Yașam döngü analizi: 1990'lardan bu yana, karar vermeye yönelik olarak Hayat Boyu Değerlendirme (Life Cycle Assessment) yöntemi kullanılmakta ve de bu araç geliştirilmeye devam etmektedir. Yöntemin temel çerçevesi, herhangi bir üretim veya hizmet sürecinin tüm girdi ve çıktılarının alternatifleri ile birlikte değerlendirilerek bütünsel bir atık bertaraf ve çevresel etkilerin değerlendirme sürecini kapsamaktadır. Çevre mühendisliği bu aracın kullanımında yetkin tek mühendislik dalıdır.

\subsection{Havza Yönetimi}

Havzaların sağladığı hidrolojik hizmetlerin muhafaza edilmesi, havzadaki toprak, su, biyolojik çeşitlilik ve diğer doğal kaynakların toplumun yararına sürdürülebilir olarak kullanımıdır. Diğer bir ifade ile havza yönetimi; bir havza sınırı içerisinde kalan toprak, su, bitki örtüsü varlığı ile bunları etkileyen bir faktör olarak da insan faaliyetlerinin birlikte ele alındığı bir doğal kaynak yönetimidir. İlgili yönetimin planını oluşturacak ve işletecek anahtar ise havza yönetim ilkeleridir.

Entegre havza yönetimi; su kaynaklarının, ilgi gruplarının katılımıyla, havza ölçeğinde ele alındığı bir planlama anlayışıdır. Bu yaklaşımda, tüm kesimlerin görüş, beklenti ve amaçlarını dengeleyecek bir planlama, organizasyon ve kontrol mekanizması uygulanması esas alınır. Entegre havza yönetiminin özellikleri arasında;

- Havzada yaşanan çok çeşitli problemleri ve bunların ilişkilerini ele alır,

- Toplumun her kesimi ile birlikte tüm eko sisteme hitap eder,

- Uzun vadede sürdürülebilir kalkınmayı amaçlar, gelecekteki problem ve beklentiler üzerine çalışmalar yapar,

- Bütünleşik havza yönetiminin sosyal bütünlüğ̈̈ ele alışı çok geniştir, toplumun bu şekilde eğitilmesini hedefler,

- Devletin tüm kuruluşları arasında koordinasyonun sağlamak yer almalıdır (URL-4 2018).

Entegre havza yönetimi ile su kaynaklarının o havzada yaşayan tüm paydaşların söz hakkının alınarak ve de en önemli olarak ekosistemin korunmasını önceleyen planlama anlayışı uygulanmaktadır. Çevre mühendisleri atık kontrolü, arıımı ya da kirlilik önleme faaliyetleri gibi pek çok çalışmayı havza boyutunda değerlendirme yetkiliğinde olabilmelidir. Bu nedenle çevre mühendisliği eğitimi sürecinde havza yönetimi bilinci yalnızca çevrebilim ya da ÇED dersi kapsamında birikim kazandırmaya yeterli olamayacaktır. Bu kapsamda, mevcut çevre mühendisliği bölümleri internet sitelerinde yayımlanmakta olan dönemlik ders programları değerlendirildiğinde 16 dersin havza yönetimi bilgi birikimi ile ilişkili olduğu görülmektedir (Tablo 2).

Tablo 2: Çevre mühendisliği bölümlerinde ekosistem/havza yönetimi ilişkili dersler

\begin{tabular}{lc}
\hline Dersin adı & Dersin verildiği bölüm sayıs1 \\
\hline Kaynak yönetimi & 7 \\
ÇED & 32 \\
Çevre yönetimi/sistemleri & 12 \\
Çevresel risk değerlendirilmesi & 2 \\
Çevre ve enerji & 8 \\
İklim değişimi & 6 \\
Çevre (mühendislik) ekonomisi & 21 \\
Kent planlaması ve çevre & 8 \\
Kirlilik önleme & 2 \\
Avrupa Birliği çevre politikaları & 3 \\
Şehir planlaması ve çevre & 8 \\
Çevre politikası /hukuku & 25 \\
Çevre mühendisliğinde etik & 7 \\
Ekosistem 1slahı / Havza yönetimi & 1 \\
Çevre toksikolojisi & 7 \\
Çevre sağlığı ve toplum & 17 \\
\hline
\end{tabular}


Çevre Mühendisliği Bölümlerinde bir öğrencinin lisans eğitimi sırasında aldığı toplam ders sayısı ve saati üniversitelere göre değişmekte, bununla birlikte genel ders grubu dağılımı da değişmektedir. Örneğin, Akdeniz Üniversitesi'nden mezun olmak için gerekli ders sayısı 58 iken bu sayı Atatürk Üniversitesi'nde 42'dir. Yine mesleki seçmeli ders olarak en yüksek sayı İstanbul Üniversitesi'nde bile 13 iken, Almanya'da herhangi bir mühendislik eğitimi sırasında bu sayı en az 15'tir. Ders yoğunluğu ve dağılımı her üniversiteye göre değişmektedir. Tablo 2'de ekosistem bilincine yönelik verilen dersler ve bunların toplam 34 bölümde okutulma sayıları verilmektedir. Son yıllarda hızlı bir şekilde ÇMB sayısının artması nedeniyle bazı bölümlerde sürekli öğrenci kaydı yapılamamaktadır. Genel olarak, 34 bölüm düzenli öğrenci almaktadır ve bunların içerisinde ders dağılımlarına bakıldığında tamamına yakınında ÇED dersi verilirken, bunu çevre politikası/hukuku dersi takip etmektedir.

Ülkemizde havza yönetimi genel olarak su kaynaklarının yönetimi olarak ele alınmakta, mevzuat ve idari yapı bu mekanizmaya uygun olarak işletilmektedir. Havza yönetimi üst heyetinin önemli görevleri arasında;

- Havza koruma eylem planları ve havza yönetim planlarının uygulanmasını izlemek, değerlendirmek ve ilgili kurumlara gerekli yaptırımlar için bildirimde bulunmak,

- İçme ve kullanma suyu kaynaklarının korunmasına yönelik çalışmaların takibini yapmak ve özel hükümlerin uygulamasını sağlamak,

- Su kalitesi ve miktarı ile ilgili izleme sonuçlarını ortak bir veri tabanında kayıt altına almak, ilgili havza birimleri ile paylaşmak, değerlendirilmiş ve raporlanmış izleme sonuçlarını tartışarak Havza Yönetimi Planları ile ilgili görüş oluşturmak

ifade edilmektedir (URL-5 2018).

\section{Değerlendirme}

1970’lerde yasal düzenlemelerin yapılmaya başladığını, 80’lerde büyük çevresel kazalara tanıklık ettiğimizi, 90’larda küresel ölçekte duyarlılığın geliştiğini, 21. yüzyılda ise küresel çevresel stresin arttığı ve sürdürülebilirliğe yoğunlaşıldığına tanık olmaktayız. Buna koşut olarak çevre mühendisliği eğitiminde de değişime gidilerek, su/atıksu yoğunluklu müfredata bilgisayar programlama, meteoroloji, sucul yaşam ve ekoloji konuları dahil edilip aynı zamanda hava kalitesi, tehlikeli atık yönetimi ve su yönetimi gibi seçmeli ders başlıkları dahil olmaktadır (Semerjian vd. 2004; Tansel 1994).

Kaynakların azalmasından nüfus artışının etkisine, iklim değişiminden su kıtlığına pek çok konunun tartışılmasına bir takım yaklaşımı gerekmektedir. Mühendis uzmanların yanı sıra bilim insanları, hükümet yetkilileri ve çeşitli paydaşların yer alacağı çözüm muhataplarının bir araya getirilip bir takım olarak hareket edilebilmesinde çevre mühendisleri en iyi donanıma sahip meslek dallarından biridir.

Çevre mühendisleri, iklim değişimiyle artan su ve gıda üzerindeki baskı sorunlarının çözümünün yanı sıra sürdürülebilir yönetimine de katkı koymaları gerekecektir. Su, toprak, madde ve enerjinin daha etkin kullanılmasında çevre mühendisleri, toplumun yönetimi ve çevrenin inşasının düzenlenmesinde yardımcı olacaklardır. İklim değişimi ile başta tarıma olan/olacak etkilerinin yanı sıra su kıtlıkları da dünyamızı yoğun olarak etkileyecektir. Çevre mühendisleri, suyun yeniden kullanımı, dezenfeksiyonu ve dağıtımı konularında yetkin olmalıdırlar. Olumsuz iklim koşulları ile baş edebilecek donanımlar kazanmalıdırlar.

Çevre mühendisliği, moleküler ölçekten başlayarak tüm ekosistemi içine alan küresel ölçeklerdeki araştırmaları ve bu farklı ölçekler arasındaki ilişkileri de ele almalıdır. Ayrıca hızla değişen ve gelişen yeni çevre teknolojilerinin yer aldığı dersler ve çevre kirliliğini önleme ve minimizasyonu konularını kapsayan derslerin sayısı oldukça azdır.

Arıtma ve üretim teknolojilerindeki bu hızlı dönüşüm çevre mühendisliği eğitimi veren üniversitelerde yeterince değerlendirilememekte ve eğitim programlarının bu değişim ve dönüşüme uyum sağlayacak şekilde revize edilmesinde geç kalınmaktadır. Teknolojilerdeki bu değişim, çevre mühendisliği eğitiminde yeni ders programlarının lisans ve yüksek lisans düzeyinde açılmasını ve özellikle mühendis adaylarının bu yeni kavramları anlamaları için temel ve uygulamalı yeni derslerin programlanmasını gerektirmektedir.

Çalışma alanlarının genişlemesiyle çevre mevzuatı, risk yönetimi, afet yönetimi gibi alanlarda beceri kazandıracak sertifika programlarına da çevre mühendislerinin talepleri olacaktır. Bununla birlikte yeşil teknolojiler, iklim değişimi, enerji verimliliği, küresel kıyı alanları, afet yönetimi gibi yeni alanlarda da yoğunlaşmalar olmaktadır. ABD'de çevre mühendisliği eğitimi verilen bölümlerde profesyonel olarak çalışma alanları arasında erozyon ve sediment kontrolünü içeren doğal çevrenin korunması ve havza yönetimi de sayılmaktadır (URL-6 2017). Çevre mühendisliği iş ilanlarında taşkın mühendisliği kapsamında çevre yöneticisi, doğal kaynak uzmanı gibi pozisyonlar da yer almaktadır (URL-7 2017).

Stratejik Çevresel Değerlendirme Yönetmeliği 2017 baharında yayımlanmıştır (URL-8 2018). Hem ulusal hem de uluslararası düzeyde ÇMB'nin ders içerikleri değerlendirildiğinde bu şekilde hızla gelişen çevre mevzuatı ve ekolojik bakış açısına uygun gelişimin buna koşut olmadığı görülmektedir. Çevre mühendisliği eğitimi, problemlerin çözümünde noktasal yaklaşımların yanı sıra ekosistemin korunmasını önceleyen çaba içerisinde olmalıdır. Doğal sistemlerin özümseme ve yeniden üretme kapasitelerini ortaya koyabilecek bilgi birikimi aktarabilmelidir. Sürdürülebilir teknolojilerin kullanımının yaygınlaşması ile yenilenebilir kaynakların kullanım hızı kendi üretilme hızlarını geçmemesine katkı sunacak ve ayrıca kalıcı ve biyolojik-birikim gösteren malzemelerin kullanımından uzaklaşılması sağlanacaktır. 
Ülkemizde havza yönetiminde söz sahibi üç kurumsal yapı (Çevre ve Şehircilik Bakanlı̆̆ı, Orman ve Su İşleri Bakanlığı, Havza Yönetim Heyeti) işleyiş açısından çevresel faaliyetleri havza bazında değerlendirme gerekliliğini belirtmiş olup, bu nedenle de çevre mühendisleri uygun eğitim ile donatılarak bu faaliyetlerde etkin rol almalıdır.

Tartışma bölümünü çarpıcı iki örnekle sonlandıralım. "Çoruh Nehri Hidroelektrik Gelişme Planı" çerçevesinde Çoruh Nehri ana kolu üzerinde 10 adet barajlı Hidroelektrik Santral (HES), yan kollar üzerinde 5 adedi barajlı, 17 adedi regülatörlü olmak üzere toplam 32 HES yapımı gerçekleşmektedir (Süme vd. 2017). İkinci olarak, Karadeniz bölgesinde Samsun, Bayburt, Giresun, Gümüşhane, Ordu, Rize, Trabzon, Artvin'i içine alan sekiz ilin yaylaları turizmi geliştirme kapsamında 2 bin 600 kilometrelik "yeşil yol" ile birbirine bağlanmak istenmektedir. Bahsedilen faaliyetlerin bütüncül olarak ekosistem içerisinde oluşturacağı etkileri yalnızca ÇED boyutu ile ele almak yeterli olamamaktadır. Projeler, tek başına bir baraj ya da iki köyü birbirine bağlayan kısa mesafeli bir yol yapımından öte, havzanın tamamını etki altına alan çalışmalardır. Projelerin hem yapım aşamasında hem de sonrasında nüfus dinamikleri değişmektedir. Tarım ve hayvancılık sektöründe değişimlere neden olmakta, olumlu olarak görülen turizmdeki gelişmeler aslında ekosistemin hızlıca tahrip edileceğini de bugüne kadar yaşanan süreçlerden çok açık olarak bize göstermektedir. Domino etkisi ile olumsuz bir etkinin doğa tarafından onarılamadan havzanın tamamında geri dönüşümü olmayan bir sürecin başlaması söz konusudur. Dolayısıyla çevre mühendisi bütünsel ekosistemi anlamalı ve tüm faaliyetleri havza yönetimi kapsamında değerlendirme bilgi birikimi ve deneyimi içerisinde olmalıdır.

\section{Kaynaklar}

Aksoy A., İmamoğlu İ., (2011), Çevre mühendisliğinin geleceğine yönelik görüşler, 2. Çevre Mühendisliği Eğitimi ve Meslek Alanındaki Gelişmeler Çalıştayı, TMMOB ÇMO, Antalya.

Corbitt R.A., (1989), Standart Handbook of Environmental Engineering, McGraw-Hill Inc.

Keskinler B., (2011), Çevre teknolojilerinde yeni yaklaşımlar ve çevre mühendisliği eğitimi, 2. Çevre Mühendisliği Eğitimi ve Meslek Alanındaki Gelişmeler Çalıştayı, TMMOB ÇMO, Antalya.

Peker İ., (2011), Türkiye'de ve Dünya'da çevre mühendisliği eğitimi, 2. Çevre Mühendisliği Eğitimi ve Meslek Alanındaki Gelişmeler Çalıştayı, TMMOB ÇMO, Antalya.

Samsunlu A., (1991), Çevre mühendisliği eğitimi, Türkiye'de Çevre Kirlenmesi Öncelikleri Sempozyumu Boğaziçi Üniv. İstanbul, 284-302.

Semerjian L., El-Fadel M., Zurayk R., Nuwayhid I., (2004), Interdisciplinary approach to environmental education, Journal of Professional Issues in Education Engineering and Practice, 133(3), 173-181.

Süme V., Özener, A.Y., Mete, B., (2017), Çoruh Nehri Yan Kolları Üzerinde Bulunan Hidroelektrik Santrallerin Hidroelektrik Potansiyeli, Türk Hidrolik Dergisi Türk Hidrolik Dergisi, 1(1), 1-6.

Şengil İ.A., Yurtsever M., (2011), Türkiye'deki çevre mühendisliği bölümlerinde öğretim üyesi profili, 2. Çevre Mühendisliği Eğitimi ve Meslek Alanındaki Gelișmeler Çalıștayı, TMMOB ÇMO, Antalya.

Tansel B., (1994), Outlook for environmental education in the 21st century, Journal of Professional Issues in Education Engineering and Practice, ASCE, 120(2), 129-134.

Zeren O., (1997), Türkiye'de çevre mühendisliği eğitimi ve karşılaşılan sorunlar, Türkiye'de Çevre Kirlenmesi Öncelikleri Sempozyumu II, Gebze, Kocaeli, 813-827.

URL-1, (2018), Çevre ve Şehircilik Bakanlığı Teşkilat ve Görevler, http://www.mevzuat.gov.tr/MevzuatMetin/4.5.644.pdf, [Erişim 15 Ocak 2018].

URL-2, (2018), Orman ve Su İşleri Bakanlığ Teşkilat ve Görevler, http://www.mevzuat.gov.tr/MevzuatMetin/4.5.645.pdf, [Erişim 15 Ocak 2018].

URL-3, (2018), 2017-ÖSYS Yüksekögrretim Programlarl ve Kontenjanları Kılavuzu, http://www.osym.gov.tr/TR,13263/2017-osysyuksekogretim-programlari-ve-kontenjanlari-kilavuzu.html, [Erişim 15 Ocak 2018].

URL-4, (2018), Havza nedir?, http://www.cem.gov.tr/erozyon/AnaSayfa/havza_planlama/havza_nedir.aspx?sflang=tr, [Erişim 15 Ocak 2018].

URL-5, (2018), Havza Yönetim Heyetlerinin Teşekkülü, Görevleri, https://www. resmigazete.gov.tr/eskiler/2015/05/20150520-5.htm, [Erişim 15 Ocak 2018].

URL-6, (2017), Department of Civil, Environmental, and Geo-Engineering, http://www.cege.umn.edu/prospective/graduate/ environmental.html, [Erişim 24 Kasım 2017].

URL-7, (2017), Environmental Engineering Jobs, https://www.engineerjobs.com/jobs/environmental-engineering, [Erişim 24 Kasım 2017].

URL-8, (2018), Stratejik Çevresel Değerlendirme Yönetmeliği, http://www.resmigazete.gov.tr/eskiler/2017/04/20170408-3.htm, [Erişim 15 Ocak 2018]. 